Rev. SINAPSIS, Edición № 9, Vol. 2, Diciembre 2016

ISSN $1390-9770$

\title{
Optimización en el proceso de selección de personal utilizando Algoritmos Genéticos
}

\section{Optimación de selección de personal}

Carlos AveigaPaini, M.Sc. ${ }^{(1)}$

Alex Guamán Guamán ${ }^{(2)}$

Ana Cruz Quijije Lic. ${ }^{(3)}$

${ }^{(1)}$ Universidad de Guayaquil, Guayaquil, Ecuador

${ }^{(2)}$ Universidad de Guayaquil, Guayaquil, Ecuador

${ }^{(3)}$ Universidad de Guayaquil, Guayaquil, Ecuador

Contacto: carlos.aveigap@ug.edu.ec

Receptado: 10/09/2016 Aceptado: 25/11/2016

\section{Resumen}

La propuesta se caracteriza por ser innovadora. Se presenta un estudio de Algoritmos Genéticos y metodologías aplicado al proceso de selección de personal, identificando restricciones de las técnicas con relación al problema y la forma en que fueron adaptadas, estableciendo un modelo de optimización para la toma de decisiones en la selección de personal, razón por la cual se desarrolló la aplicación web prototipo Selección de Personal utilizando Algoritmos Genéticos (SSPAG).Para el diseño se aplicó el Modelo Vista Controlador (MVC), utilizando herramientas de programación y modelado Open Source. SSPAG sugiere un candidato óptimo para uno o varios cargos, ya que en el modelo desarrollado también se planteó la asignación de varios candidatos a varios cargos. La propuesta aporta al sector organizacional, aplicando técnicas de optimización que ayuden a mejorar en este campo el desarrollo competitivo y académico.

Palabras clave: Algoritmos Genéticos, aplicación web, optimización, selección de personal, toma de decisiones

\section{Optimization in the process of selection of personnel using Genetic Algorithms} \begin{abstract}
This proposal is characterized for being innovative. An analysis of Genetic Algorithms and methodologies applied to the recruitment process is presented in order to identify limitations of the techniques in relation to the problem and how these were adapted, establishing therefore an optimal
\end{abstract}




\section{Rev. SINAPSIS, Edición № 9, Vol. 2, Diciembre 2016}

model for wise hiring decision for recruiting suitable personnel, which accounted for the development of a prototype web application using Algorithms Genetics (SSPAG). Therefore, the MODEL VIEW CONTROLLER (MVC) was applied for the design using programming tools and the Open source modelling. SSPAG suggests an ideal candidate for one or more positions as the developed model proposes the placement of various candidates for various positions. The proposal contributes to the human resource field by applying optimal techniques that help to improve in the research field the competitive development and Academic.

Key words: Genetic Algorithms, web application, optimization, recruiting personal, hiring decision

\section{Introducción}

"Los algoritmos genéticos son estrategias de búsqueda utilizadas para resolver problemas complejos" (Narváez, López-Lezama, y Velilla, 2015).

"El reclutamiento es la primera fase para ocupar un cargo en una organización. Durante esta etapa se hace uso del conjunto de técnicas y procedimientos orientados a atraer candidatos potencialmente calificados y capaces de ocupar cargos dentro de la organización" (Chiavenato I, 2000).

La selección de personal genera mayores repercusiones en el desenvolvimiento de una organización.

Los métodos tradicionales de programación no siempre son adecuados para desarrollar herramientas para toma de decisiones, suelen ser costosos y demanda una gran cantidad de recursos, por ello se propuso el uso de los algoritmos genéticos para encontrar una solución acorde a las necesidades.

"El uso de algoritmos genéticos, ha logrado obtener avances en campos diversos y siempre han demostrado soluciones nunca pensadas y una de las pocas técnicas capaces de enfrentar a los planteamientos que no pueden ser deducidos de manera mecánica" (Sánchez, Hernández, Ruiz y Vega, 2016)

"Los Algoritmos Genéticos constituyen técnicas computacionales basadas en heurísticas y fundamentos probabilísticos; deben su nombre a comparaciones biológicas de reproducción y adaptación de especies vivientes al campo computacional. El problema dado es codificado y de allí es seleccionada una 


\section{Rev. SINAPSIS, Edición № 9, Vol. 2, Diciembre 2016}

población inicial aleatoria de la cual se escogen padres, donde cada uno representa una solución potencial del problema. A estos padres les son aplicados criterios de reproducción o cruzamiento que involucran recombinaciones de los mismos y modificaciones aleatorias o mutaciones" (Cárdenas y Rojas, 2013).

Los Algoritmos Genéticos imitan este comportamiento generando una población de individuos que representan soluciones al problema, seleccionando los mejores; éstos se cruzan generando nuevos individuos. El propósito es mejorar la población de generación en generación.

"De la población inicial se seleccionan pares de cromosomas padres, dependiendo de su valor de aptitud, que intercambian su información genética para generar dos cromosomas hijos mediante el proceso de cruce. Para producir una mejor solución, los cromosomas hijos experimentan mutación, restableciendo los valores genéticos perdidos cuando la población converge demasiado rápido" (Vivas y Muñoz, 2013).

"Los algoritmos genéticos son técnicas de optimización estocástica que trabajan mediante la generación de soluciones aleatorias. Se basa en la evolución natural de los seres vivos" (Vásquez, Valdez, Campos, Campos \& Hernández, 2014).

"Los algoritmos genéticos son métodos potentes para resolver problemas de búsqueda y optimización" (Sivanandam, S. N. ;Deepa, S. N., 2008, pág. 15).

"La principal ventaja de describir las políticas de recursos humanos con modelos matemáticos es la obtención de una solución rápida, clara y fácil de interpretar por quienes toman las decisiones" (Canós, Caño\& González, 2006).

"Un algoritmo genético puede optimizar varios objetivos diferentes al mismo tiempo y añadir con cierta facilidad nuevos factores a la función de evaluación-aptitud de soluciones candidatas. Su ejecución puede ser paralelizable para la adecuada explotación de arquitecturas multinúcleo y multiprocesador" (Azketa, Gutiérrez, Di Natale, Almeida \& Marcos,2013).

Se abarcó un estudio de algoritmos genéticos y su aplicación práctica en la optimización de selección de personal, basándose en características y aptitudes de los candidatos con relación a los requerimientos 


\section{Rev. SINAPSIS, Edición № 9, Vol. 2, Diciembre 2016}

exigidos por uno o varios cargos o puestos de trabajo disponibles, desarrollando una herramienta de software prototipo para servir de soporte en la toma de decisión para la selección de personal.

\section{Materiales y métodos}

El enfoque de la investigación fue cuantitativo. El diseño de la investigación fue cualitativo debido a que la información a utilizar fue recolectada de fuentes bibliográficas como libros, revistas y artículos para responder a las variables de la investigación. Para desarrollar el software prototipo de optimización en la selección de personal usando algoritmos genéticos, se fundamentó en investigaciones bibliográficas, documentales y de campo mediante encuestas a funcionarios de empresas de la ciudad de Guayaquil, con la finalidad de encontrar una solución factible para resolver el problema de toma de decisiones.

"Los parámetros iniciales de diseño para desarrollar el algoritmo genético son: valores iniciales de entrada, elección de la señal de referencia, generación de población inicial, convertir a valor real los individuos de la población" (López, 2014).

El tamaño de la muestra obtenido fue de 151 organizaciones, aplicando el siguiente criterio:

$$
\begin{aligned}
& \qquad n=\frac{m}{e^{2}(m-1)+1} \\
& m=\text { Tamaño de la población inicial }=5000 \text { empresas de Guayaquil } \\
& e=\text { Error de estimación }=8 \% \\
& n=\text { Tamaño de la muestra }
\end{aligned}
$$

La fracción muestral $f$ con respecto a la población fue 0.030 aplicando lo siguiente:

$$
f=\frac{n}{N}=\frac{151}{5000}
$$

En relación a las encuestas realizadas al personal de talento humano de las organizaciones en Guayaquil, podemos realizar las siguientes observaciones. 
Rev. SINAPSIS, Edición № 9, Vol. 2, Diciembre 2016

Gráfico 1: Uso de técnicas de selección de personal

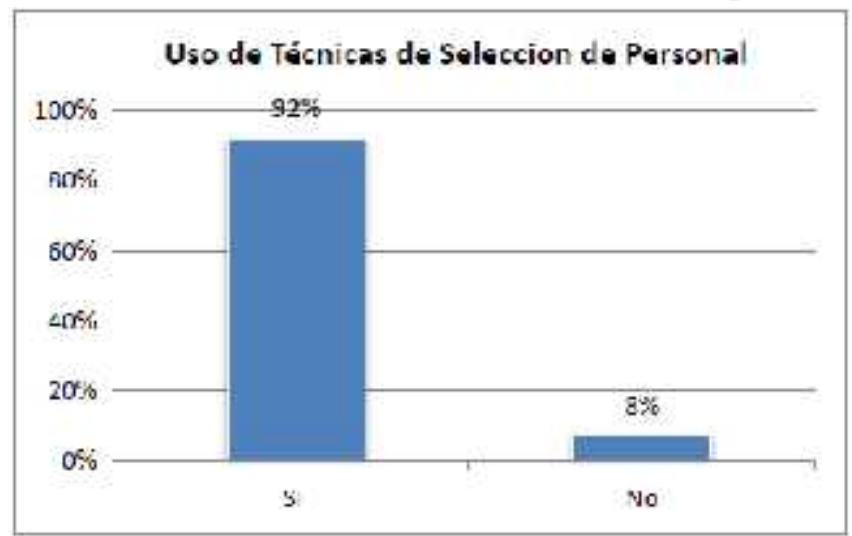

Elaborado por: Autor

El 92\% manifestó que su organización sí utilizó técnicas de selección de personal mientras que el 8\% indicó que no utilizaba debido a su reducido número de personal.

Gráfico 2: Técnicas de selección más utilizadas

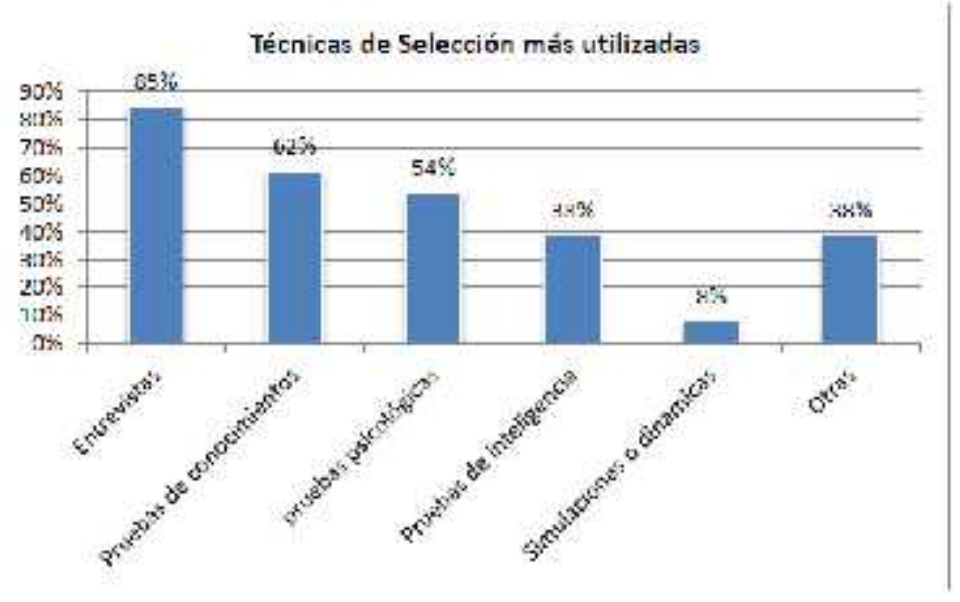

Elaborado por: Autor

La entrevista realizada a los candidatos a ocupar un cargo fue una de las principales fuentes de información mientras que un menor número de empresas realizaban pruebas de simulación o dinámicas debido al tiempo y complejidad de estas técnicas. 
Rev. SINAPSIS, Edición № 9, Vol. 2, Diciembre 2016

ISSN 1390 - 9770

Gráfico 3: Cuenta con personal capacitado para tomar pruebas

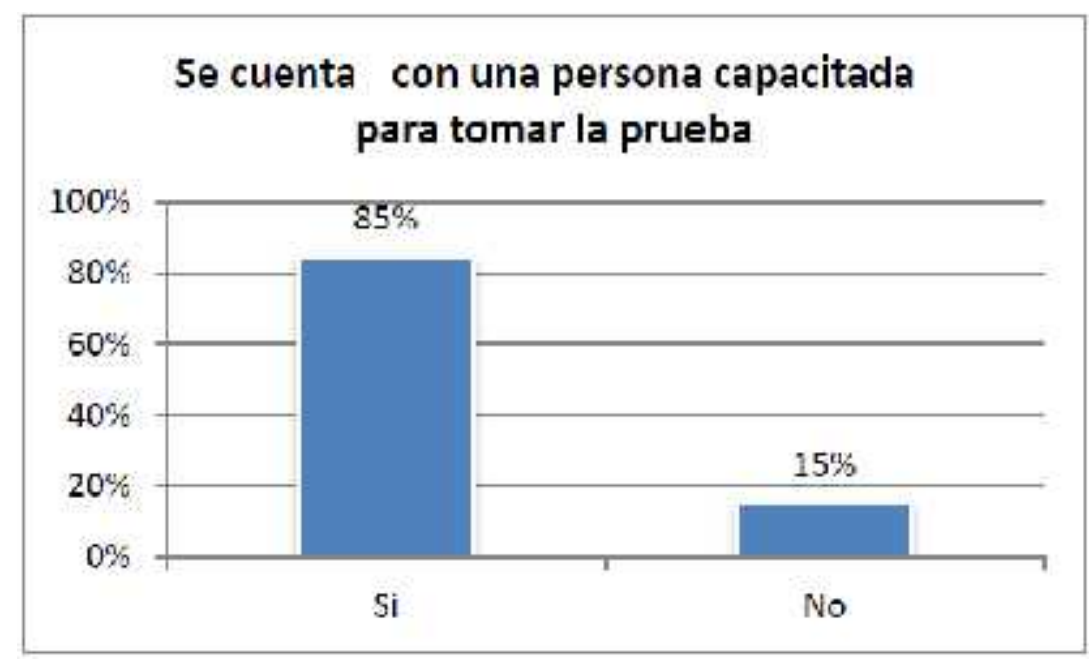

Elaborado por: Autor

El 85\% aseguraron que en su organización existe una persona capacitada para tomar pruebas para selección de personal mientras que el 15\% indicaron que las personas evaluadoras no poseen un perfil adecuado. Existe una relación entre el tamaño de la organización y la importancia que ésta brinde a la selección de Personal.

Gráfico 4: Importancia de la selección de personal

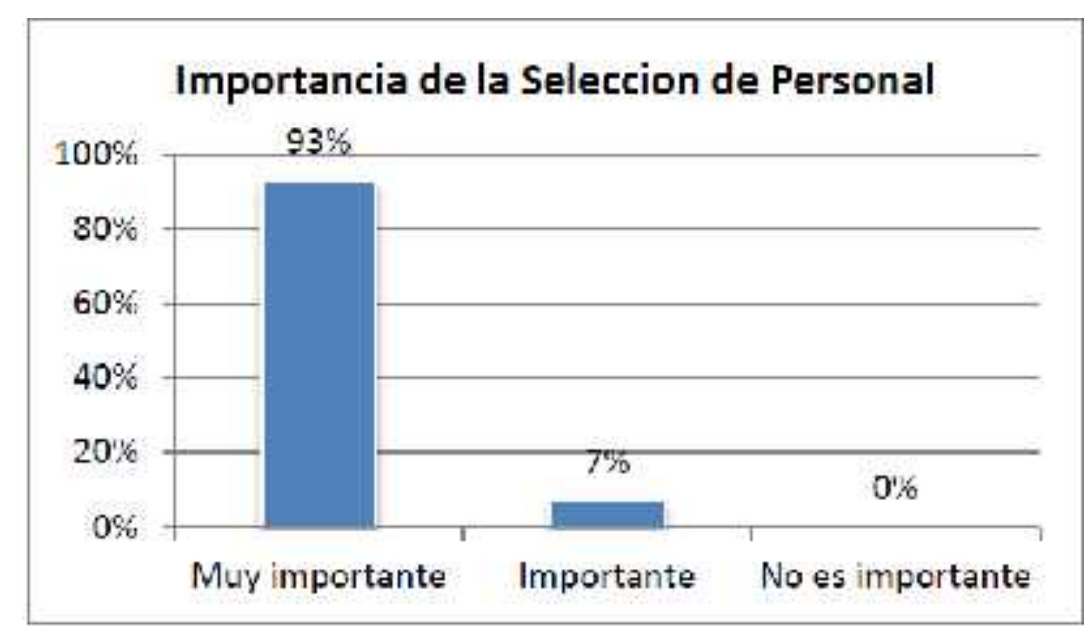

Elaborado por: Autor

El 93\% de las personas encuestadas consideran muy importante la selección de personal y el 7\% consideran que es importante. Ninguno niega su importancia. 
Rev. SINAPSIS, Edición № 9, Vol. 2, Diciembre 2016

Gráfico 5: Importancia de seleccionar un candidato óptimo

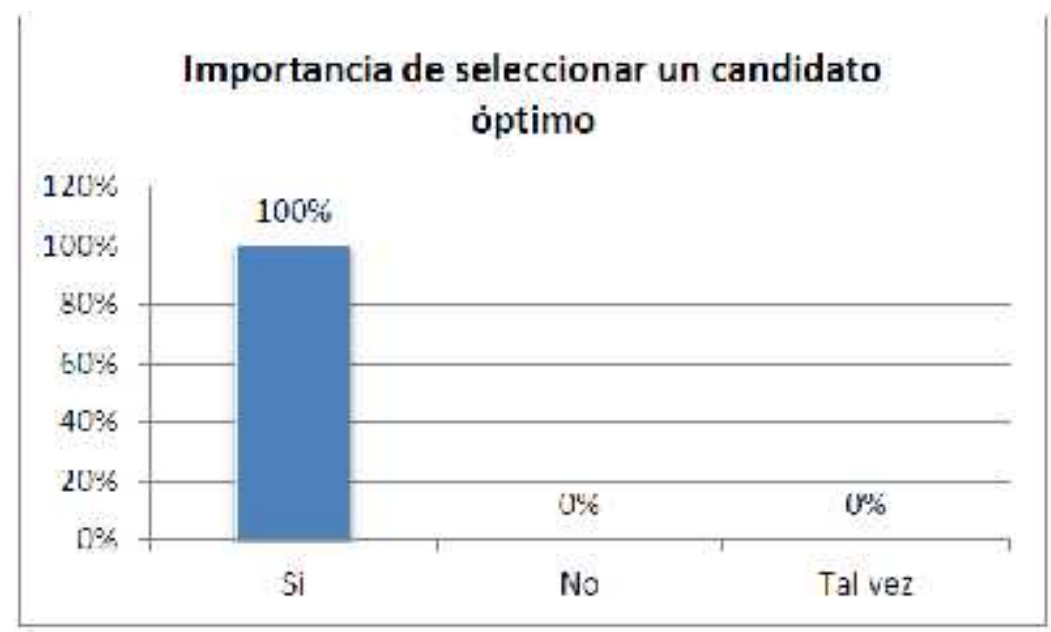

Elaborado por: Autor

El 100\% consideró importante la selección de un candidato óptimo para un cargo.

Gráfico 6: Uso de sistemas informáticos en la selección de personal

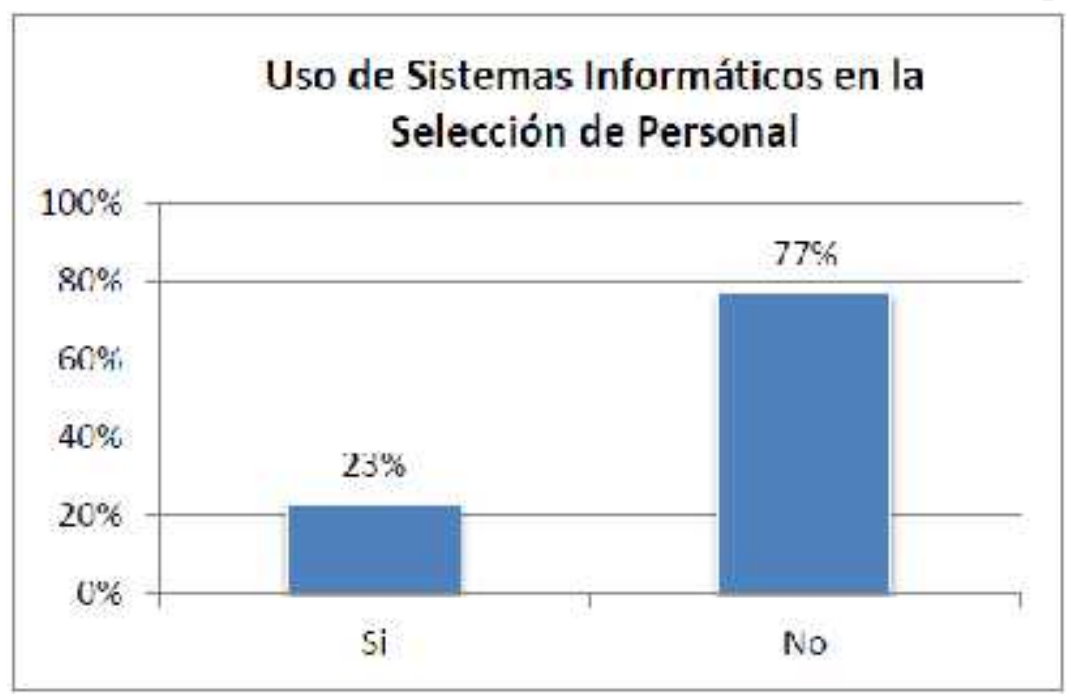

Elaborado por: Autor

El 77\% no utilizaban un sistema informático para la selección de personal, mientras que el 23\% sí lo hacían, siendo ésta una debilidad en las organizaciones.

Gráfico 7: Nivel de aceptación de un sistema que apoye en la selección de personal 


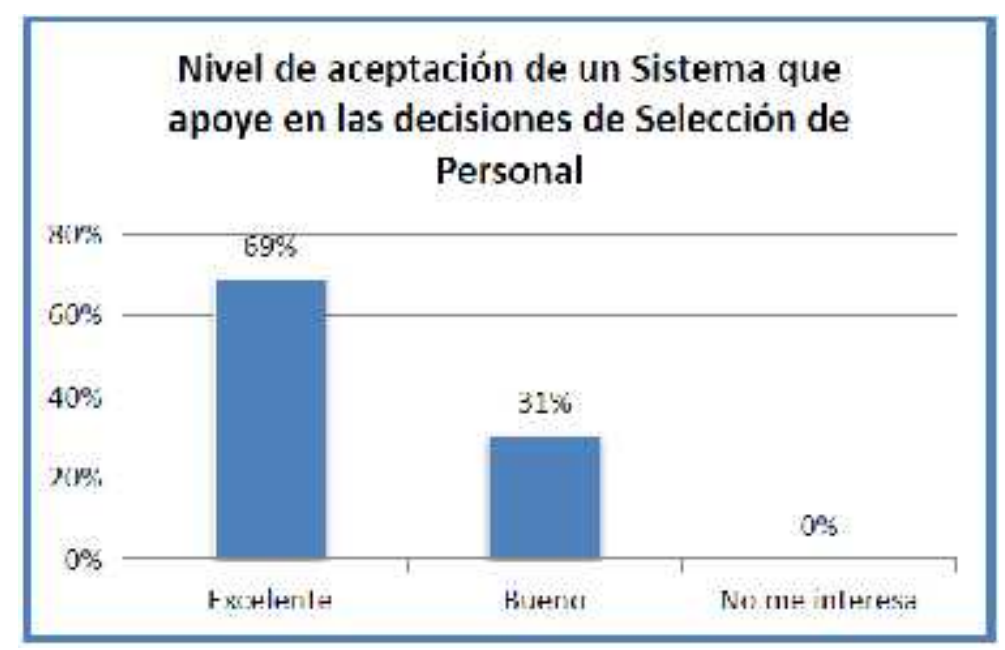

Elaborado por: Autor

El 69\% consideró que un software para apoyo en la selección de personal sería una excelente contribución para la organización, mientras que el $31 \%$ indicó que sería una buena contribución. Ninguna persona manifestó su desinterés.

Para el desarrollo del Sistema de Selección de Personal con Algoritmos Genéticos (SSPAG) se utilizó la metodología Modelo Vista Controlador (MVC) con Struts. Ésta permite seleccionar de entre un grupo de candidatos a los óptimos a ocupar un cargo, mediante la correcta alimentación de información de requisitos.

"La técnica se basa en los mecanismos de selección de la naturaleza, en que los individuos más aptos de una población son los que sobreviven al adaptarse fácilmente a los cambios que se producen en su entorno" (Ojeda, 2015).

Para el cálculo de la mejor selección de los candidatos para un cargo, se evalúan sus características frente a cada requerimiento exigido usando la Distancia de Hamming, la cual ha sido utilizada en múltiples investigaciones.

"No se debe olvidar que el éxito de cualquier organización dependerá en gran medida del recurso humano que la compone" (Chiavenato I., 2000). 
Rev. SINAPSIS, Edición № 9, Vol. 2, Diciembre 2016

"Las cualidades de empleados, conocimiento, habilidades, entusiasmo, satisfacción con el trabajo, iniciativa para generar riqueza tendrá gran impacto en la productividad de la organización, nivel de servicio al cliente, reputación, competitividad" (Chiavenato I., 2000).

Gráfico 8: Diagrama de casos de uso
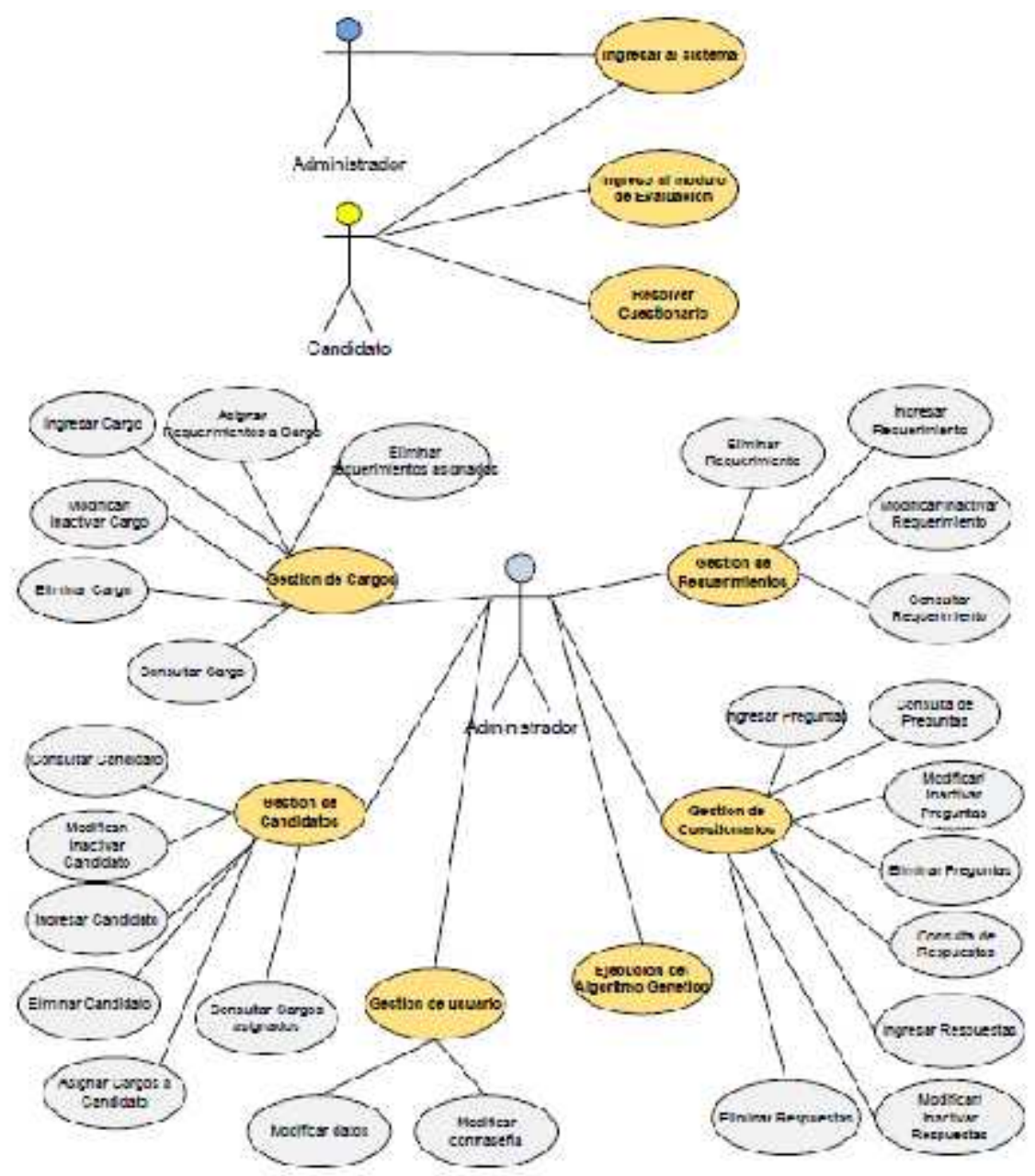

Elaborado por: Autor 
Gráfico 9: Proceso de selección de personal

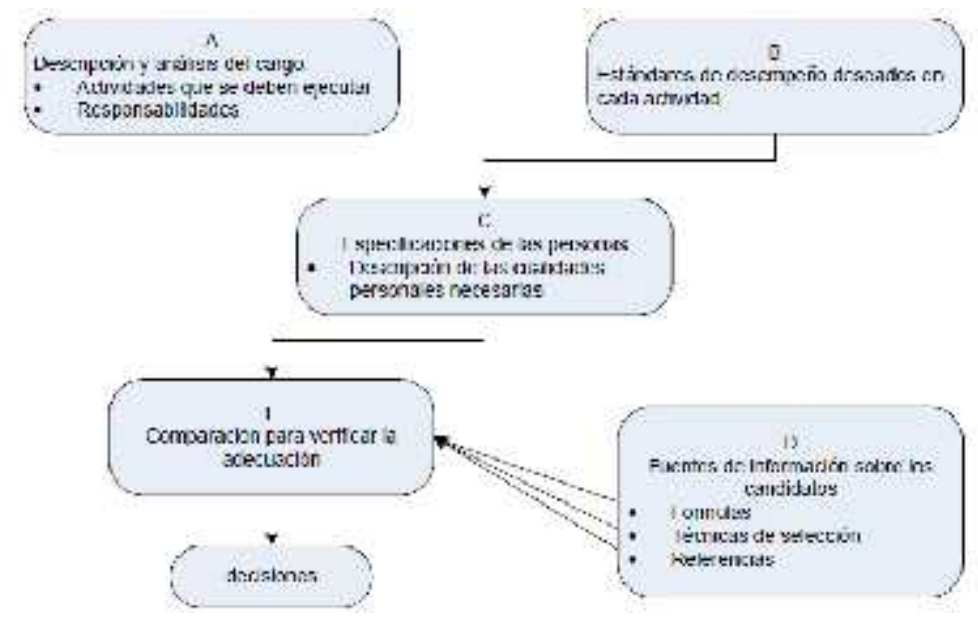

Fuente: Chiavenato Idalberto, Administración de Recursos Humanos, Quinta Edición, pág. 240

La selección de personal se fundamenta en el análisis de las especificaciones para los cargos y en las características que poseen los candidatos que compiten por un empleo, siendo un proceso de comparación y de decisión a través de 2 variables: los requisitos del cargo, que son las exigencias que deben cumplirse por el aspirante al cargo representado por la variable $x$ y el perfil de las características de los candidatos representados por $y$.

$X$ se la obtiene del análisis y la descripción del cargo, mientras que $y$ mediante la aplicación de técnicas de selección.

Cuando $x$ es mayor que $y$, el candidato no reúne las condiciones ideales para ocupar el cargo, por lo que es rechazado. Si $x$ y $y$ son iguales, el candidato posee las condiciones ideales para ocupar el cargo y es aceptado. Cuando $x$ es menor que $y$, el candidato tiene mayores condiciones que las exigidas para el cargo, lo cual no es recomendable.

Esta comparación no se centra en un punto de igualdad entre las dos variables, sino en una franja de aceptación buscando un punto cercano al ideal.

Esto puede originar tres modelos de comportamiento que se muestran en el gráfico 10. 


\section{Rev. SINAPSIS, Edición № 9, Vol. 2, Diciembre 2016}

Gráfico 10: Modelos de colocación y clasificación de los candidatos

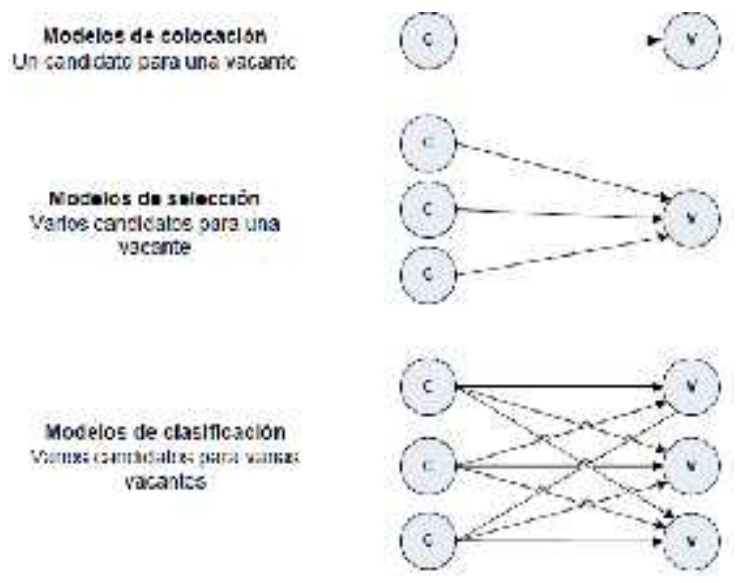

Fuente: Chiavenato, Idalberto. Pág. 243

Para este modelo se emplearon técnicas de selección que proporcionen la información necesaria de los cargos con sus especificaciones para permitir comparaciones entre los cargos y los candidatos.

"Una característica permanente en la gestión de recursos humanos es la subjetividad e incertidumbre" (Gil Aluja, 1996), lo cual complica la aplicar las técnicas clásicas de resolución de problemas. Se aplicó técnicas de lógica borrosa. Las herramientas de valoración relacionan la subjetividad con escalas de valores, de modo que los modelos matemáticos se adaptan con mayor precisión al pensamiento de los selectores, a la hora de implementar las políticas de personal en la empresa.

La toma de decisiones se realiza bajo tres situaciones: Certeza, donde se prioriza la matemática convencional; Riesgo, aplicando el cálculo de probabilidades; Incertidumbre, donde se aplicará la matemática borrosa.

Para la indeterminación, se debe considerar la lógica no bivaluada: verdadero o falso, o "lógica trivaluada": verdadero, falso o indeterminado.

A la lógica borrosa se la considera como un subconjunto de la tradicional lógica booleana extendida para manejar el concepto de parcialmente verdadero, siendo valores de verdad entre "absolutamente verdadero" y "absolutamente falso". Es una técnica usada para complementar ciertos aspectos de la 


\section{Rev. SINAPSIS, Edición № 9, Vol. 2, Diciembre 2016}

selección, sobre todo donde no es posible brindar una valoración exacta a un candidato, resultando conveniente usar lenguaje natural durante la evaluación.

"La teoría de los conjuntos borrosos (fuzzy sets), se ha desarrollado para intentar resolver problemas en los que la descripción de las actividades y las observaciones son imprecisas, vagas o inciertas, de ahí su nombre de borrosa" (Caballero, Gento y Redondo, 2005).

"En ambientes de incertidumbre la lógica borrosa brinda grandes posibilidades en el campo de la gestión de personal". (Lazzari, Machado, Pérez 1998).

"La lógica borrosa emula una de las funcionalidades "inteligentes" de los seres humanos, en este caso el razonamiento con incertidumbre." (Pajares, Santos. 2006).

Gil Aluja (1996) estudió los algoritmos de ordenación que se aplican en la selección de personal. Entre los más utilizados se encuentran la Distancia de Hamming y el Coeficiente de Adecuación.

La información de los candidatos, cargos y requerimientos se ingresaron al modelo propuesto, que a través de iteraciones o generaciones, se encargaron de realizar la selección de los resultados óptimos. La adaptabilidad de un candidato a un cargo estuvo dada por los requerimientos que éste cumpla para con el cargo.

El tamaño del cromosoma en el algoritmo genético fue dinámico para cada variación del problema, entonces el número de genes que tuvo el cromosoma dependerá del número de cargos disponibles.

Primero se estableció el número de cargos disponibles:

$$
\mathrm{A}=\left(\mathrm{P}_{1}, \mathrm{P}_{2}, \mathrm{P}_{3}, \mathrm{P}_{4}, \ldots . . \mathrm{P}_{\mathrm{n}}\right) ; \mathrm{P} \text { son los cargos. }
$$

Y el número de requerimientos asignados a los cargos:

$$
\mathrm{B}=\left(\mathrm{R}_{1}, \mathrm{R}_{2}, \mathrm{R}_{3}, \mathrm{R}_{4}, \ldots . . \mathrm{R}_{\mathrm{j}}\right) \quad ; \mathrm{R} \text { son los requerimientos. }
$$

Para cada cargo se asociaron sus requerimientos: 
Rev. SINAPSIS, Edición № 9, Vol. 2, Diciembre 2016

$Y=\left\{\begin{array}{ccc}R_{1} P_{1} & R_{1} P_{2} & R_{1} P_{3}, \ldots \ldots . . . R_{1} P_{n} \\ R_{2} P_{1} & R_{2} P_{2} & R_{2} P_{3}, \ldots \ldots . . R_{2} P_{n} \\ . . & . . & \ldots . \\ R_{m} P_{1} & R_{m} P_{2} & R_{m} P_{3}, \ldots \ldots . . R_{m} P_{n}\end{array}\right\}$

El número de candidatos que aplican a los cargos disponibles:

$\mathrm{J}=\left(\mathrm{C}_{1}, \mathrm{C}_{2}, \mathrm{C}_{3}, \mathrm{C}_{4}, \ldots . . \mathrm{C}_{\mathrm{n}}\right)$;

Para cada candidato tendremos asociados los requerimientos que en ellos se deben evaluar:

$Y=\left\{\begin{array}{ccc}R_{1} C_{1} & R_{1} C_{2} & R_{1} C_{3}, \ldots \ldots \ldots R_{1} C_{n} \\ R_{2} C_{1} & R_{2} C_{2} & R_{2} C_{3}, \ldots \ldots . . R_{2} C_{n} \\ . . & . . & . . \\ R_{m} C_{1} & R_{m} C_{2} & R_{m} C_{3}, \ldots \ldots . . R_{m} C_{n}\end{array}\right\}$

Se elaboró una matriz de información donde se almacenaron los pesos correspondientes y las valoraciones de los requerimientos de los cargos a evaluar, y otra matriz para todas las características que se dispone un candidato. Se calcularon las distancias que cada candidato tiene respecto al cargo, basados en las características y aptitudes de ellos, usando la Distancia de Hamming.

La codificación del algoritmo genético es diferente a las codificaciones binarias tradicionales, debido que los segmentos binarios generarían codificaciones no válidas. Se utilizó codificación entera-real, es decir, que los genes del individuo se representaron con números enteros o reales.

Una solución estuvo representada por un individuo o cromosoma que tuvo tantos genes como cargos se fueron evaluando. El tamaño del cromosoma dependerá del número de cargos, donde cada posición del cromosoma corresponde a un cargo. Una solución estuvo compuesta por candidatos que aspiran a un cargo, donde cada gen representa a un candidato, y su posición en el cromosoma se relaciona directamente con el cargo disponible que dicha posición representa.

La población estuvo compuesta por individuos que representan las soluciones. Para generar la población inicial, se utilizó un proceso aleatorio. Las soluciones válidas fueron obtenidas de una matriz donde las filas representan los candidatos y las columnas los cargos, es decir, una matriz de $n * m$, donde $\mathrm{n}$ es el número de candidatos y m el número de cargos existentes a evaluar. 
La función de adecuación de cada solución estuvo dada por la distancia que ésta se encuentra con el origen; mientras una solución se acerque más a cero, más posibilidades tendrá de ser seleccionada como la mejor.

Para encontrar la adecuación de cada solución se utilizó la Distancia de Haming. Se evaluaron los requerimientos del cargo con las características del candidato, y este sería el valor de adecuación de un candidato para el cargo. Basado en características y requerimientos, la función de adecuación de una solución es la suma de las adecuaciones de cada candidato con los cargos respectivamente. La solución que tienda a cero será considerada óptima ya que existe menos diferencia entre los candidatos y cargos evaluados.

La selección estuvo basada en el ranking donde las mejores soluciones fueron seleccionadas para la etapa de cruzamiento. Aplicando un método Elitista nos aseguramos que las mejor solución no desaparezca, copiándola directamente a la siguiente generación.

"La función de cruce es la que permite la creación de una nueva generación de individuos" (Sabatier, Marín, y Picado, 2016).

Se optó por un cruzamiento simple, es decir, cruce en un punto, con una variación del cruce cíclico. Esto sucedió porque al depender del número de cargos para el tamaño del cromosoma, ocasionó que varios candidatos al momento de cruce queden fuera del cromosoma. Para el proceso de cruce se seleccionaron 2 cromosomas padre y se eligió un punto de cruce al azar, dividiendo al cromosoma en dos, se intercambiaron las ristras y los genes del primer cromosoma padre con los del segundo cromosoma madre.

Como el cromosoma hijo tiene que ser una solución válida del conjunto de soluciones, no puede haber genes repetidos dentro del mismo cromosoma. En caso de que el cromosoma padre repita un gen en el cromosoma hijo, éste tomaría el gen del otro padre en la misma posición.

Para la mutación se utilizó el método de Mutación por Intercambio Repetido, eligiendo de forma aleatoria dos genes del cromosoma y se intercambiaron sus posiciones para asegurar que los individuos son 


\section{Rev. SINAPSIS, Edición № 9, Vol. 2, Diciembre 2016}

soluciones al problema. Cuando se trate de un problema de selección en el que el número de candidatos supera al número de cargos, se debe utilizar una Mutación Uniforme de Inserción de Individuos no contenidos en el cromosoma.

La condición de parada de un algoritmo genético estuvo dada por el número de generaciones o al encontrar la solución óptima.

La condición óptima se generó cuando una solución se aproxime a cero, ya que no existen candidatos $100 \%$ perfectos.

Se optó que la condición de parada del presente algoritmo se dio por el número de iteraciones conocida como generaciones. El número de iteraciones no debe ser muy bajo ya que el algoritmo genético puede quedarse a medias y mostrar un resultado inadecuado.

Para la arquitectura del sistema prototipo se utilizó una arquitectura Web 3 capas. 
Rev. SINAPSIS, Edición № 9, Vol. 2, Diciembre 2016

ISSN 1390 - 9770

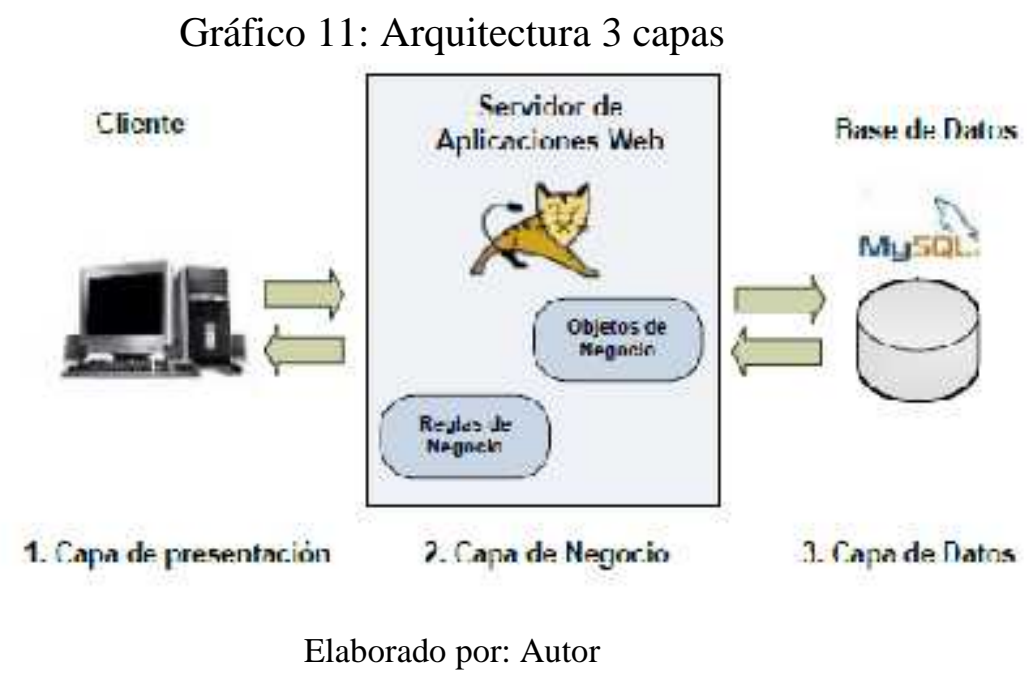

En la capa de presentación se encuentra el cliente quien hace las peticiones; en la de negocio está el servidor de aplicaciones donde se maneja toda la lógica de negocio y la lógica de acceso a la base de datos. En la tercera capa se encuentra la base de datos donde está la información que manejará la aplicación.

Para el diseño de la base de datos, para el desarrollo del modelo Entidad-Relación se utilizó la herramienta MySQL Workbench.

Gráfico 12: Modelo entidad relación 
Rev. SINAPSIS, Edición № 9, Vol. 2, Diciembre 2016

ISSN $1390-9770$

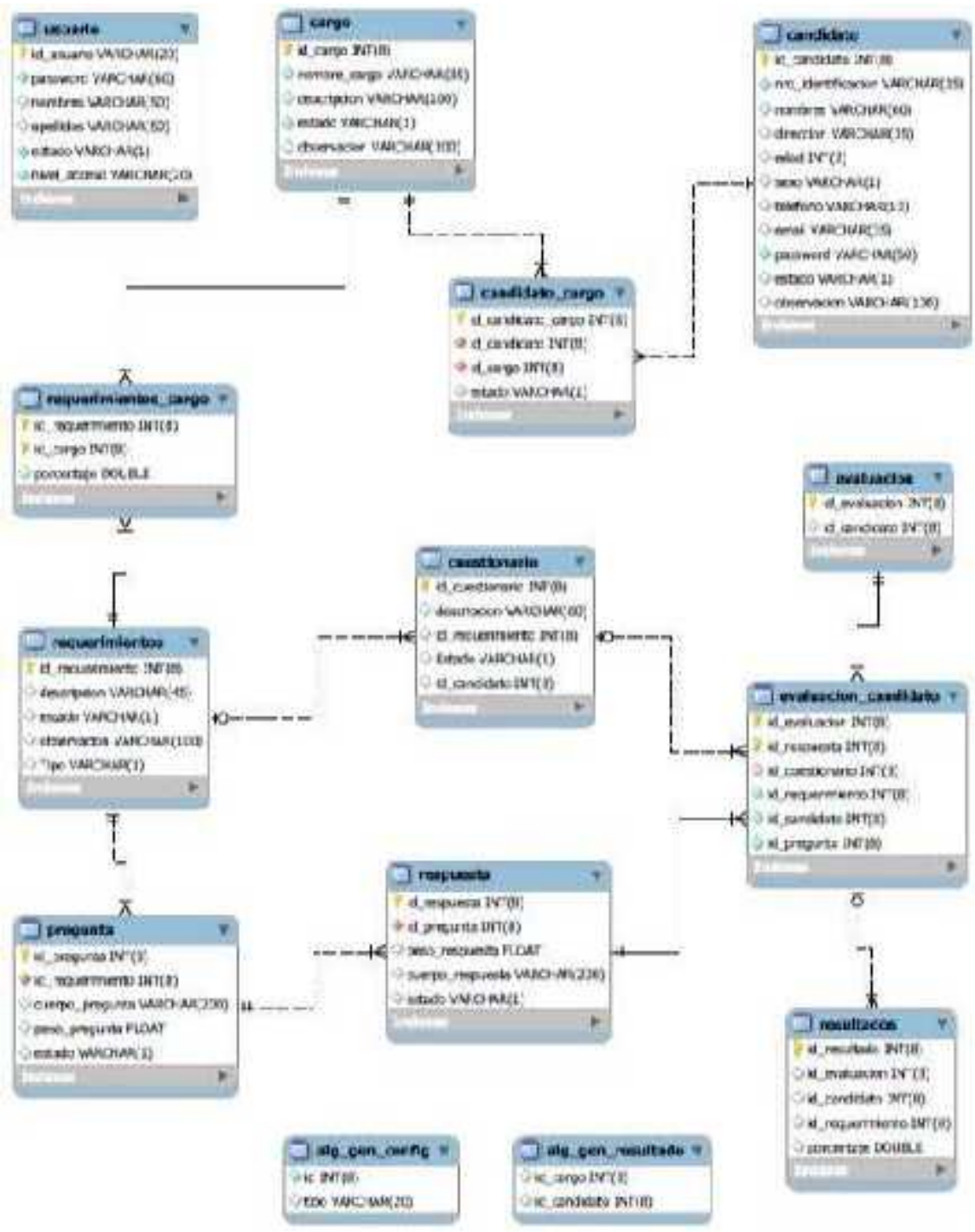

Elaborado por: Autor

Como metodología de programación se utilizó la Programación Orientada a Objetos (POO)..

Para la etapa de desarrollo del proyecto se utilizó software de licencia libre. Las herramientas utilizadas fueron: Java JSP, Eclipse 3.2.2, My Eclipse 5.5.1 GA, APJackartaTomcat 5.5, MySqlServer 5.0, SqlYog 6.16, MySqlWorkbench.

Para el desarrollo del módulo se utilizó el modelo de programación Web basado en Struts, un framework basado en el patrón Modelo Vista Controlador desarrollado por The Apache Software Foundation. Es Open Source y se utiliza para desarrollar aplicaciones web en Java. Se crearon páginas Jsp, aplicando Struts, Xml y JavaScript. 
El diseño del software prototipo es sencillo y minimalista, mostrando lo que el usuario realmente necesita y le será útil, además permite interactuar con el sistema de manera rápida y eficiente. Struts trata de simplificar el modelo MVC ya que el Controlador se encuentra implementado por Struts y el workflow de la aplicación se configuró desde un archivo XML.

Una de las ventajas de trabajar con Struts es que separa el desarrollo de la interfaz y la lógica de negocio.

\section{Gráfico 13: Página de login}

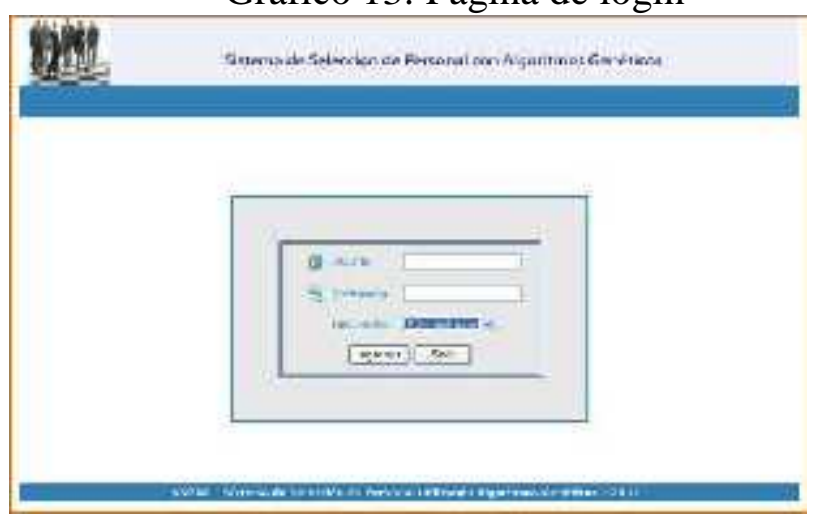

Elaborado por: Autor

Gráfico 14: Página de modificación de datos de usuario

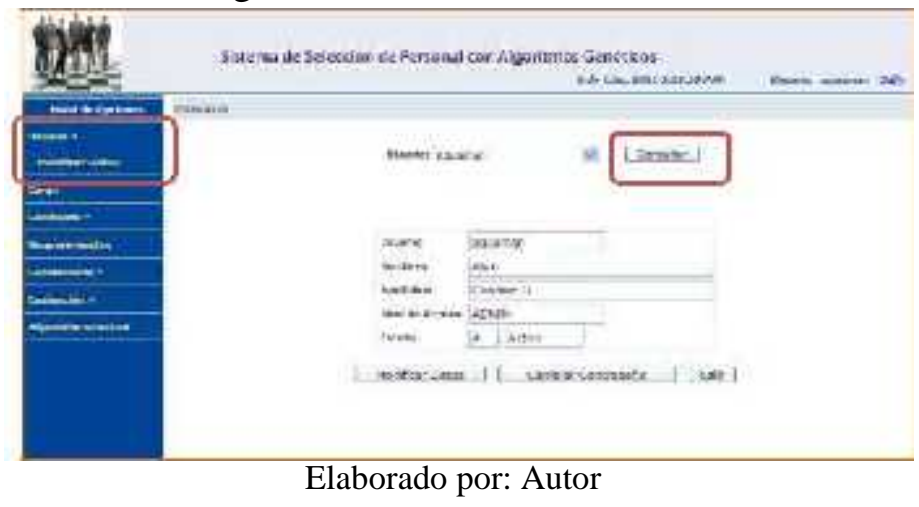




\section{Rev. SINAPSIS, Edición № 9, Vol. 2, Diciembre 2016}

Gráfico 15: Página de ingreso de cargos

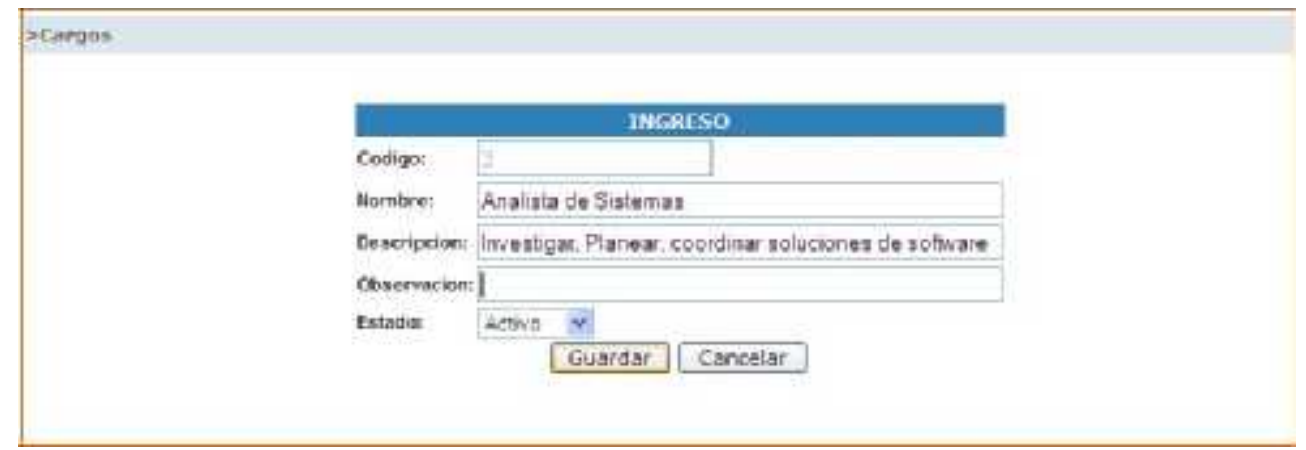

Elaborado por: Autor

Gráfico 16: Página de asignación de requerimientos al cargo

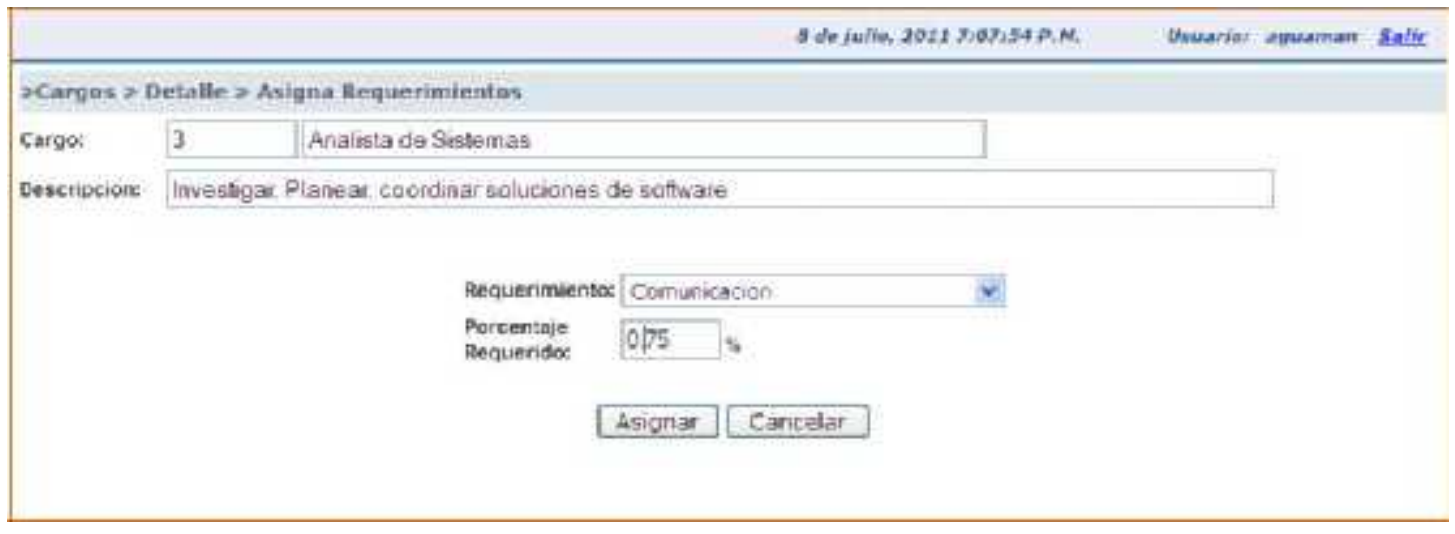

Elaborado por: Autor

\section{Resultados}

Para las pruebas se ingresó 4 cargos a ser evaluados. A estos cargos se le asignaron los requerimientos que fueron evaluados. Mediante técnicas de selección de personal evaluamos las capacidades o características de cada uno de los candidatos, para observar cuál de ellos se ajustó más adecuadamente al perfil de cada uno de los cargos, manteniendo siempre en cuenta que el candidato óptimo es aquel que más se acerca o posee los niveles de requerimientos que los cargos necesitan, es decir, el candidato no debe estar subestimado ni sobreestimado con respecto al cargo.

Para la prueba de ejecución mostrada en la Tabla 1, se muestra la configuración de los parámetros del algoritmo genético.

Tabla 1. Configuración del algoritmo genético 1 
Rev. SINAPSIS, Edición № 9, Vol. 2, Diciembre 2016

ISSN 1390 - 9770

\begin{tabular}{|l|l|}
\hline Población & 40 \\
\hline Selección & Uniforme \\
\hline Probabilidad de cruce & 0.70 \\
\hline Probabilidad de Mutación & 0.1 \\
\hline Generaciones & 40 \\
\hline
\end{tabular}

Elaborado por: Autor

Utilizando un método de selección Uniforme, la ejecución del algoritmo genético tuvo el siguiente comportamiento.

Tabla 2: Evolución del algoritmo genético utilizando selección uniforme

\begin{tabular}{|r|c|c|}
\hline Generación & Cromosoma & Fitness \\
\hline 1 & $2-1-5-3$ & 0,35833333 \\
\hline 2 & $2-1-3-6$ & 0,42833333 \\
\hline 3 & $2-1-3-6$ & 0,42833333 \\
\hline 4 & $2-1-5-3$ & 0,35833333 \\
\hline 5 & $2-1-3-6$ & 0,42833333 \\
\hline 6 & $2-1-3-4$ & 0,34833333 \\
\hline 7 & $2-1-3-4$ & 0,34833333 \\
\hline 8 & $1-2-3-4$ & 0,35785714 \\
\hline 9 & $1-2-3-4$ & 0,35785714 \\
\hline 10 & $2-1-3-4$ & 0,34833333 \\
\hline 11 & $2-1-3-4$ & 0,34833333 \\
\hline 12 & $2-1-3-4$ & 0,34833333 \\
\hline 13 & $2-1-3-4$ & 0,34833333 \\
\hline 14 & $2-1-3-4$ & 0,34833333 \\
\hline 15 & $2-1-3-4$ & 0,34833333 \\
\hline 16 & $2-1-3-4$ & 0,34833333 \\
\hline 17 & $2-1-3-4$ & 0,34833333 \\
\hline 18 & $2-1-3-4$ & 0,34833333 \\
\hline & & \\
\hline
\end{tabular}


Rev. SINAPSIS, Edición № 9, Vol. 2, Diciembre 2016

\begin{tabular}{|r|r|r|}
\hline 19 & $2-1-3-4$ & 0,34833333 \\
\hline 20 & $2-1-3-6$ & 0,42833333 \\
\hline 21 & $1-2-3-5$ & 0,41785714 \\
\hline 22 & $1-2-3-5$ & 0,41785714 \\
\hline 23 & $1-2-3-5$ & 0,41785714 \\
\hline 24 & $1-2-3-5$ & 0,41785714 \\
\hline 25 & $2-1-6-3$ & 0,48333333 \\
\hline 26 & $2-1-5-6$ & 0,4283333 \\
\hline 27 & $1-2-5-4$ & 0,35785714 \\
\hline 28 & $2-1-5-4$ & 0,34833333 \\
\hline 29 & $2-1-5-4$ & 0,34833333 \\
\hline 30 & $2-1-5-4$ & 0,34833333 \\
\hline 31 & $2-1-5-4$ & 0,34833333 \\
\hline 32 & $2-1-5-4$ & 0,34833333 \\
\hline 33 & $2-1-5-4$ & 0,3483333 \\
\hline 34 & $2-1-5-4$ & 0,34833333 \\
\hline 35 & $2-1-5-4$ & 0,34833333 \\
\hline 36 & $2-1-5-4$ & 0,34833333 \\
\hline 37 & $2-1-5-4$ & 0,34833333 \\
\hline 38 & $2-1-5-4$ & 0,34833333 \\
\hline 39 & $2-1-5-4$ & 0,34833333 \\
\hline 40 & $2-1-5-4$ & 0,34833333 \\
\hline & & \\
\hline
\end{tabular}

Elaborado por: Autor

Gráfico 17: Evolución del algoritmo genético utilizando un método de selección uniforme 


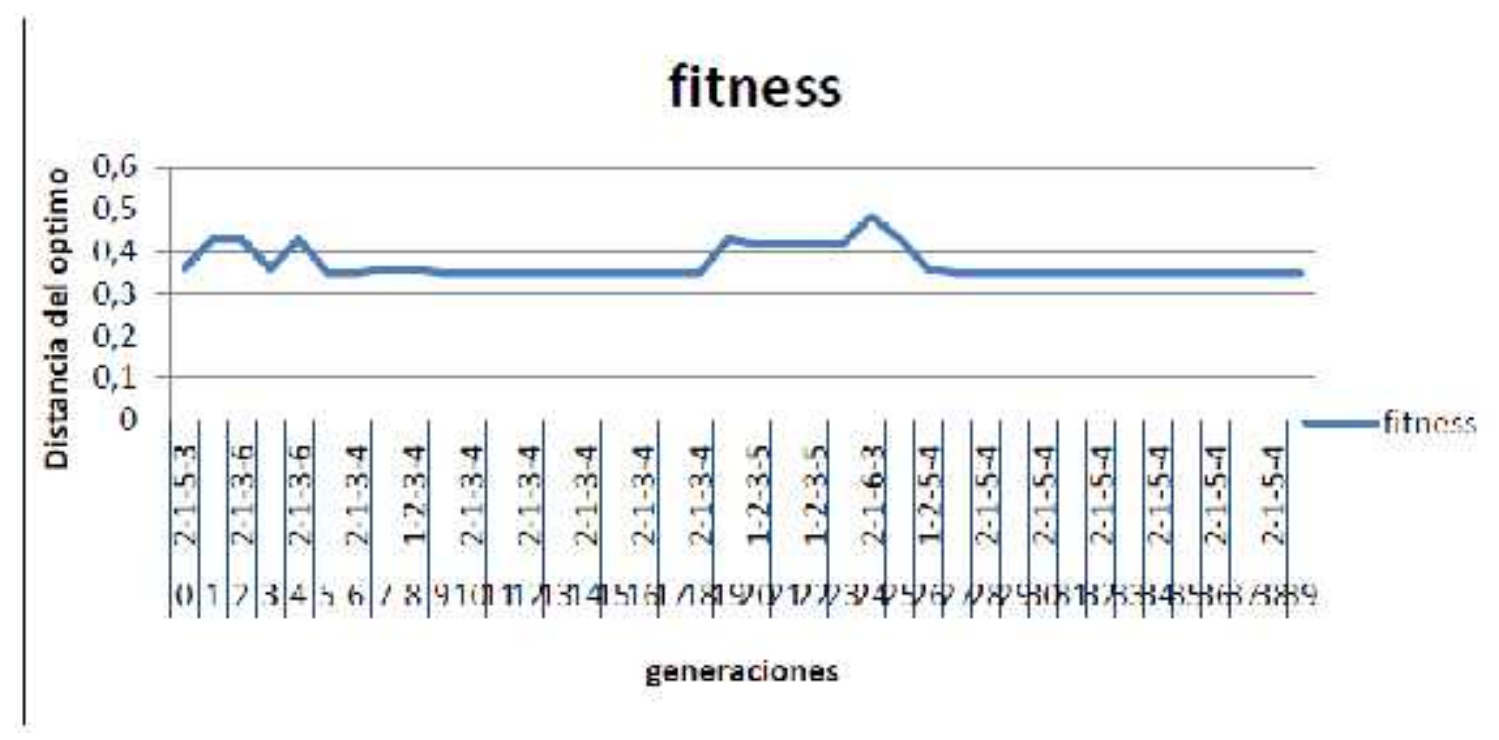

Elaborado por: Autor

Luego de haber encontrado un individuo óptimo, éste fue reemplazado por un individuo menos óptimo, porque el individuo óptimo fue cruzado con otro perdiendo en este punto sus mejores genes o sufrió una mutación que no favoreció su genoma.

Al utilizar un método de selección Uniforme, éste no discriminó las buenas soluciones de las malas, pudiendo descartar las buenas soluciones durante la ejecución.

Para contrarrestar el escenario anterior, se utilizó el método Elitista que conserva los mejores cromosomas intactos hasta que no a parezca uno mejor para reemplazarlo.

Según Díaz (2015), "el método Elitista es un método de selección que consiste en copiar al mejor individuo de la población y conservarlo a través de las generaciones hasta que se encuentre un individuo mejor y se actualice el individuo guardado. Es utilizado debido a que el uso de los operadores de cruce y mutación tiene una alta probabilidad de perder a los mejores individuos de la población durante las generaciones. Cabe recalcar que la utilización de este operador puede mejorar el algoritmo genético al conservar la mejor solución".

Tabla 3: Configuración del algoritmo genético 2

\begin{tabular}{|c|c|}
\hline Población & 40 \\
\hline Selección & Elitista \\
\hline
\end{tabular}


Rev. SINAPSIS, Edición № 9, Vol. 2, Diciembre 2016

\begin{tabular}{|c|c|}
\hline Prob. de Cruce & 0.70 \\
\hline Prob. de Mutación & 0.1 \\
\hline Generaciones & 40 \\
\hline
\end{tabular}

Elaborado por: Autor

Tabla 4: Evolución del algoritmo genético utilizando selección Elitista

\begin{tabular}{|r|c|c|}
\hline Generación & Cromosoma & Fitness \\
\hline 1 & $1-2-5-3$ & 0,36785714 \\
\hline 2 & $1-2-5-3$ & 0,36785714 \\
\hline 3 & $1-2-5-4$ & 0,35785714 \\
\hline 4 & $1-2-5-4$ & 0,35785714 \\
\hline 5 & $1-2-5-4$ & 0,35785714 \\
\hline 6 & $2-1-5-4$ & 0,34833333 \\
\hline 7 & $2-1-3-4$ & 0,34833333 \\
\hline 8 & $2-1-5-4$ & 0,34833333 \\
\hline 9 & $2-1-5-4$ & 0,34833333 \\
\hline 10 & $2-1-3-4$ & 0,34833333 \\
\hline 11 & $2-1-3-4$ & 0,34833333 \\
\hline 12 & $2-1-3-4$ & 0,34833333 \\
\hline 13 & $2-1-3-4$ & 0,34833333 \\
\hline 14 & $2-1-3-4$ & 0,34833333 \\
\hline 15 & $2-1-3-4$ & 0,34833333 \\
\hline 16 & $2-1-3-4$ & 0,34833333 \\
\hline 17 & $2-1-3-4$ & 0,34833333 \\
\hline 18 & $2-1-3-4$ & 0,34833333 \\
\hline 19 & $2-1-3-4$ & 0,34833333 \\
\hline 20 & $2-1-3-4$ & 0,34833333 \\
\hline 21 & $2-1-3-4$ & 0,34833333 \\
\hline 22 & $2-1-3-4$ & 0,34833333 \\
\hline 23 & $2-1-3-4$ & 0,34833333 \\
\hline & & \\
\hline &
\end{tabular}


Gráfico 18: Evolución del algoritmo genético utilizando un método de selección elitista

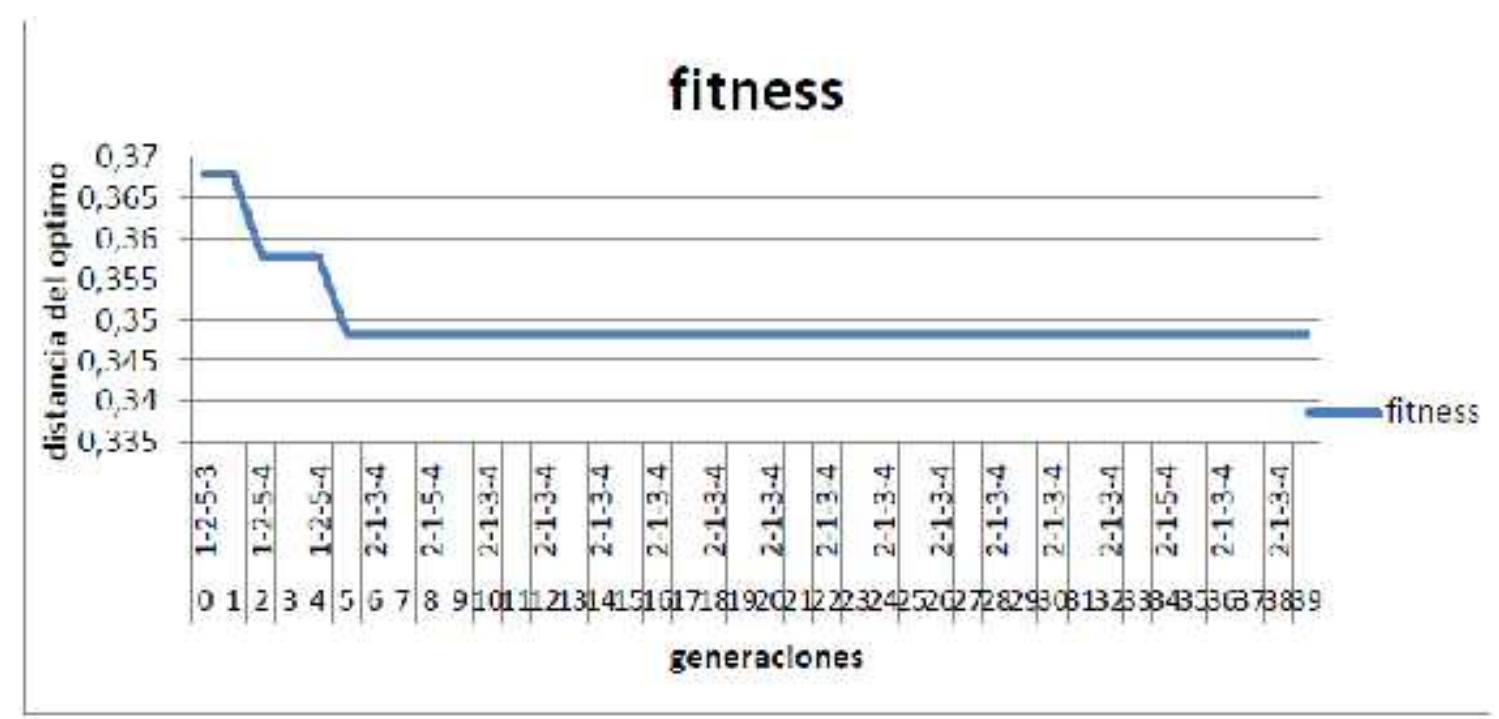

Elaborado por: Autor

El algoritmo genético Elitista convergió en la primera generación en la que el valor del mejor cromosoma se mantuvo hasta que apareció otro mejor. Una elevada población inicial también ayudó a encontrar una solución adecuada de manera rápidamente.

Acorde al plan de pruebas realizado a la aplicación web prototipo Selección de Personal utilizando Algoritmos Genéticos (SSPAG) tal como se muestra en la Tabla 5, las diferentes funciones de la aplicación fueron sometidas a múltiples ensayos reales, entre ellas las clasificamos en: 5 ingresos, 9 consultas, 7 modificaciones, 8 eliminaciones, 3 asignaciones, determinamos que la aplicación pasó satisfactoriamente todas las pruebas.

Tabla 5: Plan de pruebas

\begin{tabular}{|l|c|l|}
\hline \multicolumn{1}{|c|}{ Función } & $\begin{array}{c}\text { Resultados de las } \\
\text { pruebas }\end{array}$ & \multicolumn{1}{|c|}{ Observación } \\
\hline Ingresa Cargo & Correcto & Ingresado correctamente \\
\hline Consulta Cargo & Correcto & Consultado correctamente \\
\hline
\end{tabular}


Rev. SINAPSIS, Edición № 9, Vol. 2, Diciembre 2016

\begin{tabular}{|c|c|c|}
\hline Modifica Cargo & Correcto & Modificado correctamente \\
\hline Elimina Cargo & Correcto & Eliminado correctamente \\
\hline Ingresa Requerimiento & Correcto & Ingresado correctamente \\
\hline Consulta Requerimiento & Correcto & Consultado correctamente \\
\hline Modifica Requerimiento & Correcto & Modificado correctamente \\
\hline Elimina Requerimiento & Correcto & Eliminado correctamente \\
\hline Ingresa Candidato & Correcto & Ingresado correctamente \\
\hline Consulta Candidato & Correcto & Consultado correctamente \\
\hline Modifica Candidato & Correcto & Modificado correctamente \\
\hline Elimina Candidato & Correcto & Eliminado correctamente \\
\hline Ingresa Pregunta & Correcto & Ingresado correctamente \\
\hline Consulta Pregunta & Correcto & Consultado correctamente \\
\hline Modifica Pregunta & Correcto & Modificado correctamente \\
\hline Elimina Pregunta & Correcto & Elimina correctamente \\
\hline Ingresa Respuesta & Correcto & Ingresado correctamente \\
\hline Consulta Respuesta & Correcto & Consultado correctamente \\
\hline Modifica Respuesta & Correcto & Modificado correctamente \\
\hline Elimina Respuesta & Correcto & Eliminado correctamente \\
\hline Asigna Requerimiento de Cargo & Correcto & Ingresado correctamente \\
\hline Consulta Requerimiento de Cargo & Correcto & Consultado correctamente \\
\hline Modifica Requerimiento de Cargo & Correcto & Modificado correctamente \\
\hline Elimina Requerimiento de Cargo & Correcto & Eliminado correctamente \\
\hline Asigna un Cargo a Candidato & Correcto & Ingresado correctamente \\
\hline Consulta un Cargo a Candidato & Correcto & Consultado correctamente \\
\hline Elimina un Cargo a Candidato & Correcto & Eliminado correctamente \\
\hline Asigna Evaluación a Candidato & Correcto & Ingresado correctamente \\
\hline Consulta Evaluación de Candidato & Correcto & Consultado correctamente \\
\hline Elimina Evaluación de Candidato & Correcto & Eliminado correctamente \\
\hline Califica Cuestionarios & Correcto & Ejecutado correctamente \\
\hline
\end{tabular}


Rev. SINAPSIS, Edición № 9, Vol. 2, Diciembre 2016

\begin{tabular}{|l|l|l|}
\hline $\begin{array}{l}\text { Consulta Resultados de } \\
\text { Cuestionarios }\end{array}$ & Correcto & Consultado correctamente \\
\hline Modifica Datos de Usuario & Correcto & Modificado correctamente \\
\hline Cambia contraseña & Correcto & Modificado correctamente \\
\hline Ejecución del Algoritmo Genético & Correcto & Ejecutado correctamente \\
\hline
\end{tabular}

Elaborado por: Autor

\section{Discusión}

Un aspecto interesante fue el desarrollo de la aplicación web prototipo en base a la lógica borrosa, o difusa, en el estudio de la teoría de la incertidumbre, que comparándolo con su tradicional forma de desarrollo de aplicaciones de software en la selección de personal utilizando el lenguaje natural propio del ser humano, se encontró que existió una mayor funcionalidad de la lógica borrosa.

La herramienta es útil para ayudar en el proceso de Selección de Personal, seleccionando a los candidatos cuyas características más se adapten a los requerimientos de los cargos disponibles, pero esto va a depender mucho de la información que se obtenga de los cargos, de los candidatos y la manera en que estos datos se obtengan.

\section{Conclusiones}

La herramienta presentada permitirá seleccionar a uno o varios candidatos para uno o varios puestos de trabajo, sea en un proceso de selección individual, como en un proceso de asignación de personal en el que se tiene varios cargos disponibles. Cabe destacar que la importancia del algoritmo genético es notoria en un proceso de asignación de cargos de varios candidatos, varios cargos a evaluar y donde la cantidad de combinaciones posibles sea significativa.

El uso de herramientas de software libre para el desarrollo de la aplicación web prototipo minimiza su costo significativamente.

El proyecto se desarrolló considerando su escalabilidad facilitando el desarrollo y cambios a futuro al utilizar la metodología Modelo Vista Controlador, la cual facilita el trabajo en paralelo, diseñando de una manera organizada las vistas por un lado y la lógica de negocio por el otro. 
Rev. SINAPSIS, Edición № 9, Vol. 2, Diciembre 2016

Para próximas investigaciones se sugiere la optimización del diseño de los cuestionarios para poder abarcar en su mayoría los diferentes test correspondientes a la selección de personal.

Se recomienda que el contenido de los cuestionarios sea realizado por personas de profesiones afines a la selección de Personal, ya que de esto va a depender la valoración que cada candidato va a tener respecto a un cargo.

\section{Referencias Bibliográficas}

1) Azketa, E., Gutiérrez, J. J., Di Natale, M., Almeida, L., \& Marcos, M. (2013). Algoritmo genético permutacional para el despliegue y la planificación de sistemas de tiempo real distribuidos. Revista Iberoamericana de Automática e Informática Industrial RIAI, 10(3), 344-355.

2) Cárdenas, R. C., \& Rojas, A. (2013). Minimización de una función de orden p mediante un algoritmo genético. Publicaciones en Ciencias y Tecnología, 7(1), 23-35.

3) Chiavenato, Idalberto.(2000). "Administración de Recursos Humanos". Editorial McGraw Hill Interamericana S.A., Colombia.

4) Díaz, A., \& Nataly, A. (2015). Elaboración de una solución metaheurística usando un algoritmo genético que permita elaborar la distribución de los horarios académicos.

5) Gil Aluja, J. (1996): "La Gestión Interactiva de los Recursos Humanos en la Incertidumbre". Centro de Estudios Ramón Areces. Madrid-España.

6) López, C. R. (2014). Evaluación de desempeño de dos técnicas de optimización bio-inspiradas: Algoritmos Genéticos y Enjambre de Partículas.Tekhnê, 11(1), 49-58.

7) Narváez, P. A., López-Lezama, J. M., \& Velilla, E. (2015). Ubicación de Generación Distribuida para Minimización de Pérdidas Usando un Algoritmo Genético Híbrido. Informacióntecnológica, 26(3), 123-132. 


\section{Rev. SINAPSIS, Edición № 9, Vol. 2, Diciembre 2016}

8) Ojeda, J. C. (2015). A methodbasedongeneticalgorithms to support TEA diagnosis Un método basado en algoritmos genéticos de apoyo al diagnóstico TEA. Actas de Ingeniería, 1, 84-93.

9) Pajares Martinsaz, Gonzalo. Santos Peñas, Matilde.(2006). Inteligencia Artificiale Ingeniería del Conocimiento. Facultad de Informática. Universidad Complutence de Madrid. RA -MA Editorial. 1era edición Alfa Omega Grupo Editor, México.

10) Sabatier, Y. S., Marín, M. C., \& Picado, L. T. (2016). Implementación de un algoritmo genético para la asignación de aulas en un centro de estudio.Uniciencia, 22(1), 115-121.

11) Sánchez, M. A., Hernández, S. I., Ruiz, N., \& Vega, G. (2016). Hacia la optimización de recursos escolares basada en la aplicación de algoritmos genéticos. Boletín Científico INVESTIGIUM de la Escuela Superior de Tizayuca, 1(1).

12) Sivaraj, R., Ravichandran, T., Priya, D.(2012). Solving traveling salesman problem using clustering genetic algorithm.International Journal on Computer Science and Engineering (IJCSE), 4, 1310 1317. ISSN: 0975-3397.

13) Sivanandam, S. N. ;Deepa, S. N.(2008). “Introduction to Genetic Algorithms”.Springer Berlin Heidelberg.New York. Derechos de Autor: Sivanandam, Deepa, USA.

14) Tanasanne, P.(2014). Clustering evolutionary computation for solving travelling salesman problems International Journal of Advanced Computer Science and Information Technology (IJACSIT), 3, (3), 243-262, ISSN: 2296-1739.

15) Vásquez, L., Valdez, A., Campos, G., Campos, R., \& Hernández, R. (2014). Programación paralela en una técnica de optimización de tiempos de producción de una empresa. de Cuerpos Académicos, 60.

16) Vivas, Á. M. R., \& Muñoz, J. C. C. (2013). Adaptación del algoritmo genético para la creación de árboles de enrutamiento en una red de sensores inalámbrica. Lámpsakos, (10), 34-42 